\title{
Ethical dilemmas associated with genetic testing: which are most commonly seen and how are they managed?
}

\author{
Natalie McLean, BSc, $\mathrm{M}^{1,2}$, Martin B. Delatycki, MBBS, $\mathrm{PhD}^{1-3}$, Ivan Macciocca, BSc, MHSc ${ }^{2,4}$ \\ and Rony E. Duncan, BSC, PhD ${ }^{1,2,5}$
}

\begin{abstract}
Purpose: The aim of this study was to document the range and frequency of ethical dilemmas associated with genetic testing encountered by genetic health professionals and to determine the strategies used to manage them.

Methods: An online survey was used to document how often the 11 key ethical dilemmas have been encountered; whether any additional dilemmas have been encountered; and how these dilemmas have been managed. Members of the Australasian Association of Clinical Geneticists, Australasian Society of Genetic Counsellors, and genetic social workers practicing in Australia and New Zealand were invited to participate.
\end{abstract}

Results: A total of 102 responses were received (31\% response rate). Respondents had encountered all of the 11 ethical dilemmas included in the survey, and 18 respondents had encountered 14 addi- tional dilemmas. Respondents encountered an average of 2.2 dilemmas per year of practice. Peer and clinical supervision were the most common strategies used to manage dilemmas, and seeking advice from clinical ethics committees was rare. Occasionally, respondents facilitated practices they deemed unethical as a consequence of client deception.

Conclusion: Ethical dilemmas of genetic testing are encountered regularly in clinical genetics practice. Evidence provided by our study can assist in targeting training, support, and guidance to help genetic health professionals navigate such dilemmas in the future.

Genet Med 2013:15(5):345-353

Key Words: ethics; genetic counseling; genetic testing; genetics; professional practice patterns

\section{INTRODUCTION}

Clinical genetics has developed rapidly over the past several decades as a consequence of increased understanding of the human genome and the widespread availability of genetic testing for many conditions. Along with this development have come significant ethical concerns about the use of genetic testing. As the field continues to grow and public awareness increases, the provision of genetic tests will fall not just to genetic health professionals, but to a range of health professionals more broadly. Calls for better training in genetics for medical practitioners, for example, are already commonplace in the literature. ${ }^{1}$

Genetic testing can be highly beneficial. Identification of preventable reproductive risk and exclusion or identification of a known familial increased risk of cancer, providing the ability to apply risk-reducing strategies, are but two examples. However, these benefits come with many potential ethical dilemmas. Although there is a large body of literature concerned with ethical dilemmas of genetic testing, there are very few empirical studies documenting dilemmas that arise in clinical practice, with most publications simply referring to hypothetical dilemmas, rather than actual past cases. ${ }^{2-11}$ Only a small proportion of empirical research in this area focuses on the experiences of genetic health professionals in relation to actual ethical dilemmas of clinical practice.
Previous studies focusing on ethical dilemmas in clinical genetics can largely be divided into three categories: those that focus on a single ethical dilemma, ${ }^{2-4,6-22}$ those that discuss the ethical dilemmas encountered in association with a single genetic condition, such as Huntington disease, ${ }^{23-25}$ and those that provide an overview of ethical dilemmas. ${ }^{26-34}$

Studies that provide an overview of ethical dilemmas use a range of methodologies, including the use of hypothetical scenarios, ${ }^{29,31,33}$ case scenarios, ${ }^{30,34}$ focus groups, ${ }^{32}$ and surveys. ${ }^{26-28}$ However, none of these studies have documented the comprehensive range of ethical dilemmas currently encountered in practice. They do not provide specific data concerning the frequency of ethical dilemmas encountered or the range of management strategies used when ethical dilemmas of genetic testing arise. Therefore, there is limited information about the current incidence of ethical dilemmas in clinical genetics practice, leaving uncertainty about whether theoretical assumptions about potential ethical dilemmas are borne out in clinical practice.

This study aimed to document the range and frequency of ethical dilemmas occurring in clinical genetic testing in Australasia. The study also aimed to document the management strategies used when such ethical dilemmas of genetic testing arise.

\footnotetext{
${ }^{1}$ Department of Paediatrics, University of Melbourne, Parkville, Victoria, Australia; ${ }^{2}$ The Bruce Lefroy Centre, Murdoch Childrens Research Institute, Parkville, Victoria, Australia; ${ }^{3}$ Department of Clinical Genetics, Austin Health, Heidelberg, Victoria, Australia; ${ }^{4}$ Victorian Clinical Genetics Services, Murdoch Childrens Research Institute, Parkville, Victoria, Australia; ${ }^{5}$ Centre for Adolescent Health, Murdoch Childrens Research Institute, Parkville, Victoria, Australia. Correspondence: Rony E. Duncan (rony.duncan@mcri.edu.au)
} 


\section{MATERIALS AND METHODS}

Survey development

The survey contained two sections: demographics and ethical dilemmas (see Supplementary Data online). To develop the section concerning ethical dilemmas, the research team identified a range of key ethical dilemmas from past literature and discussions with colleagues. These were then reviewed and narrowed down to 11 mutually exclusive ethical dilemmas through dialogue within the research team and with clinical colleagues. A summary of these 11 ethical dilemmas is presented in Table 1.

Respondents were asked a series of questions about each of the 11 ethical dilemmas, which included whether they had encountered the dilemma, how many times they had encountered it, and the range of strategies they had used to manage it. Management strategies identified in previous studies were used as a guide for drafting the range of management strategies to include in the survey for each ethical dilemma, ${ }^{27,28}$ although respondents were also able to specify additional management strategies if the list provided in the survey was not exhaustive. If the ethical dilemma related to the provision of a genetic test (as opposed to, for example, a dilemma about whether to disclose information obtained as a consequence of a genetic test), respondents were also asked how often they had refused to provide such a test. At the end of each ethical dilemma, an openended question asked for further comments. This section also allowed respondents to provide information about additional ethical dilemmas they had encountered in relation to genetic testing.

The survey was piloted on three genetic counselors and one clinical geneticist. Their comments and recommendations were used to amend the survey before it was sent out to the wider cohort of potential respondents.

Table 1 The 11 key ethical dilemmas included in the survey of genetic health professionals

\begin{tabular}{|c|c|c|c|}
\hline & Dilemma & Definition & Ethical issue(s) \\
\hline 1 & Misattributed paternity ${ }^{6}$ & $\begin{array}{l}\text { The situation in which the assumed father is } \\
\text { not the biological father. }\end{array}$ & $\begin{array}{l}\text { Whether to disclose the information and if } \\
\text { so to whom. }\end{array}$ \\
\hline 2 & Incest ${ }^{21}$ & $\begin{array}{l}\text { A sexual relationship between two close } \\
\text { relatives, e.g., father and daughter or } \\
\text { siblings. }\end{array}$ & $\begin{array}{l}\text { Whether to disclose the information and if } \\
\text { so to whom; whether to report to the legal } \\
\text { authorities. }\end{array}$ \\
\hline 3,4 & $\begin{array}{l}\text { Predictive testing of immature/mature minors } \\
\text { for adult-onset conditions }{ }^{12,17}\end{array}$ & $\begin{array}{l}\text { Testing of someone who has not reached } \\
\text { the age of majority for a condition that } \\
\text { generally has onset in adulthood and for } \\
\text { which no effective prevention is available. }\end{array}$ & $\begin{array}{l}\text { Whether it is acceptable to override the } \\
\text { child's future autonomy (for immature } \\
\text { minors); whether testing will cause harm to } \\
\text { the child (for immature and mature minors). }\end{array}$ \\
\hline 5 & Predictive testing of competent third parties ${ }^{25}$ & $\begin{array}{l}\text { Genetic testing of someone who has full } \\
\text { mental capacity without his/her knowledge } \\
\text { or consent, at the request of a relative or } \\
\text { other third party. }\end{array}$ & $\begin{array}{l}\text { Whether it is acceptable to test } \\
\text { competent individuals without informed } \\
\text { consent; whether the needs of a third party } \\
\text { can ever outweigh those of the person being } \\
\text { tested. }\end{array}$ \\
\hline 8 & Sex selection for nonmedical reasons ${ }^{2,9,15,20}$ & $\begin{array}{l}\text { Making use of PGD or prenatal testing to } \\
\text { determine the sex of an embryo/fetus to } \\
\text { fulfill parental wishes for a child of a specific } \\
\text { gender. }\end{array}$ & $\begin{array}{l}\text { Whether it is appropriate to use genetic } \\
\text { technologies to balance families or facilitate } \\
\text { cultural or personal beliefs about gender } \\
\text { preference. }\end{array}$ \\
\hline 9 & Selection for a disability ${ }^{3,10}$ & $\begin{array}{l}\text { Selection of embryos or a fetus using genetic } \\
\text { technologies to ensure the birth of a child } \\
\text { with a disability. }\end{array}$ & $\begin{array}{l}\text { How to determine appropriate limits to } \\
\text { procreative autonomy; whether the use of } \\
\text { genetic technology should be limited to } \\
\text { avoiding disability. }\end{array}$ \\
\hline
\end{tabular}




\section{Recruitment}

The 71 members of the Australasian Association of Clinical Geneticists and 247 members of the Australasian Society of Genetic Counsellors who had listed their e-mail addresses with these organizations, plus 10 genetic social workers in Australasia, via direct contact, were invited to participate in the online survey between May and July 2011. Completed surveys were submitted anonymously online. Respondents were sent two reminder e-mails a fortnight apart after the initial invitation, and the survey was available online for a month following the last of these reminders. Respondents were also informed that once they had completed the survey they could elect to enter a prize draw for a $\$ 100 \mathrm{gift}$ voucher. To be eligible for the survey, respondents were required to see clients on a regular basis for genetic consultation. To be eligible for analysis, respondents were required to have completed questions in the survey concerning at least one ethical dilemma.

\section{Data analysis}

Quantitative analysis of the survey was performed using Stata 12.2 data analysis and statistics software (StataCorp, College Station, TX). Both descriptive and inferential statistics were used to analyze demographic and professional characteristics and responses related to each of the ethical dilemmas. Comparisons were made between the responses of clinical geneticists and genetic counselors using $\chi^{2}$ tests. Genetic social workers were excluded from inferential analysis because of the small number of respondents $(n=4)$ as compared with the other genetic health professions (26 clinical geneticists and 72 genetic counselors).

The frequency of each ethical dilemma was calculated by dividing the total number of cases encountered by all respondents by the total number of years all respondents had been practicing.

Open-ended questions regarding additional ethical dilemmas encountered and additional management strategies used were categorized using content analysis by multiple members of the research team to ensure consistency. ${ }^{35}$ This involved placing each response into a category to describe the type of ethical dilemma it represented, and then comparing and contrasting these categories until a final list of mutually exclusive and discrete categories was achieved. All four authors were involved in this process until consensus was reached.

\section{Ethics committee approval}

Ethics committee approval was obtained from the Royal Children's Hospital, Melbourne, (HREC-31070A) and the University of Melbourne (1135986).

\section{Respondents}

\section{RESULTS}

Responses were received from 31 members of the Australasian Association of Clinical Geneticists, 84 members of the Australasian Society of Genetic Counsellors, and 5 genetic social workers. Of these respondents, two listed their profession as "researcher," one as "oncologist," and one as "family history assessor," and were therefore excluded from the analysis. Responses from one clinical geneticist and eight genetic counselors were also excluded from analysis because these individuals did not see clients for genetic consultation on a regular basis. Responses from one clinical geneticist, three genetic counselors, and one genetic social worker were excluded because they did not provide any responses to the questions concerning ethical dilemmas.

The remaining 102 responses (31.3\% response rate) from 26 clinical geneticists (37.6\% response rate), 72 genetic counselors (29.1\%), and 4 genetic social workers $(40.0 \%)$ were analyzed in detail. The Australasian Society of Genetic Counsellors was unable to provide the exact number of professionals on their list who were practicing genetic counselors, and so it is likely that the response rate is an underestimation through inclusion of those not currently practicing and thus not eligible to respond.

\section{Demographics}

The demographic information provided by respondents is summarized in Table 2. Most respondents were female (84.0\%), aged 49 years or younger $(78.8 \%)$, and Caucasian $(94.7 \%)$. The mean number of years that respondents had been practicing was 9.9 years $(\mathrm{SD}=7.9)$, and the mean number of clients they saw per week was $6.6(\mathrm{SD}=3.3)$. A majority of respondents spent $\geq 50 \%$ of their time on client-related activities $(78.7 \%)$.

\section{Ethical dilemmas encountered}

Each of the 11 ethical dilemmas included in the survey had been encountered by at least some of the respondents. Table 3 summarizes the number of respondents who had encountered each of these ethical dilemmas.

Three of the ethical dilemmas were encountered by over half of the respondents: testing at $25 \%$ risk (encountered by 71 respondents $(71.0 \%)$ ); requests for predictive genetic testing of mature minors (encountered by 68 respondents $(67.3 \%)$ ), and nondisclosure of genetic status to at-risk relatives (encountered by 63 respondents $(63.0 \%))$.

The only two ethical dilemmas demonstrating statistically significant differences between participant groups were requests for predictive genetic testing of mature and immature minors. In these cases, a much higher percentage of clinical geneticists had encountered these ethical dilemmas in comparison with genetic counselors.

The ethical dilemma encountered by respondents most frequently was nondisclosure of genetic status to at-risk relatives $(0.5$ cases per year of practice $(\mathrm{SD}=1.0))$. Overall, respondents encountered an average of 2.2 ethical dilemmas per year of practice $(\mathrm{SD}=2.3)$.

A total of 18 respondents reported 14 additional ethical dilemmas (Table 4) they had encountered regarding genetic testing that were not included in the survey. The most common of these dilemmas, each reported by three respondents, were clients who declined to receive results from predictive testing and requests for genetic testing of individuals who had reduced cognitive capacity or who lacked social support. 
Table 2 Respondent demographic information according to profession

\begin{tabular}{|c|c|c|c|c|c|c|c|c|c|}
\hline \multirow[b]{2}{*}{ Variable } & \multicolumn{2}{|c|}{$\begin{array}{l}\text { Clinical geneticists } \\
\quad(n=26)\end{array}$} & \multicolumn{2}{|c|}{$\begin{array}{l}\text { Genetic counselors } \\
\qquad(n=72)\end{array}$} & \multicolumn{2}{|c|}{$\begin{array}{l}\text { Genetic social workers } \\
\qquad(n=4)\end{array}$} & \multicolumn{2}{|c|}{$\begin{array}{c}\text { Total } \\
(N=102)\end{array}$} & \multirow[b]{2}{*}{$P$ value $^{\text {a }}$} \\
\hline & $n$ & $\%$ & $n$ & $\%$ & $n$ & $\%$ & $n$ & $\%$ & \\
\hline Gender ${ }^{b}$ & & & & & & & & & $<0.01^{c}$ \\
\hline Female & 11 & 47.8 & 64 & 95.5 & 4 & 100.0 & 79 & 84.0 & \\
\hline Male & 12 & 52.2 & 3 & 4.5 & - & - & 15 & 16.0 & \\
\hline Age, years ${ }^{b}$ & & & & & & & & & $<0.01^{c}$ \\
\hline $20-34$ & 1 & 4.3 & 33 & 49.3 & - & - & 34 & 36.2 & \\
\hline $35-49$ & 15 & 65.2 & 24 & 35.8 & 1 & 25.0 & 40 & 42.6 & \\
\hline$\geq 50$ & $\cdot 7$ & 30.4 & 10 & 14.9 & 3 & 75.0 & 20 & 21.3 & \\
\hline Ethnicity ${ }^{b}$ & & & & & & & & & 0.49 \\
\hline Caucasian & 21 & 91.3 & 64 & 95.5 & 4 & 100.0 & 89 & 94.7 & \\
\hline Other & 2 & 8.7 & 3 & 4.5 & - & - & 5 & 5.3 & \\
\hline Years in the profession & & & & & & & & & $<0.01^{c}$ \\
\hline $1-5$ & 5 & 19.2 & 33 & 45.8 & 1 & 25.0 & 39 & 38.2 & \\
\hline $6-10$ & 5 & 19.2 & 19 & 26.4 & 1 & 25.0 & 25 & 24.5 & \\
\hline $11-20$ & 8 & 30.8 & 19 & 26.4 & 1 & 25.0 & 28 & 27.5 & \\
\hline$>20$ & 8 & 30.8 & 1 & 1.4 & 1 & 25.0 & 10 & 9.8 & \\
\hline Consultations per week & & & & & & & & & $<0.01^{c}$ \\
\hline $1-5$ & 7 & 26.9 & 32 & 44.4 & 4 & 100.0 & 43 & 42.2 & \\
\hline $6-10$ & 14 & 53.8 & 37 & 51.4 & - & - & 51 & 50.0 & \\
\hline $11-20$ & 5 & 19.2 & 3 & 4.2 & - & - & 8 & 7.8 & \\
\hline $\begin{array}{l}\% \text { Time spent on } \\
\text { client work per week }^{\text {b }}\end{array}$ & & & & & & & & & 0.65 \\
\hline$<25 \%$ & 2 & 8.7 & 4 & 6.0 & 1 & 25.0 & 7 & 7.4 & \\
\hline $26 \%-50 \%$ & 4 & 17.4 & 9 & 13.4 & - & - & 13 & 13.8 & \\
\hline $51 \%-75 \%$ & 7 & 30.4 & 27 & 40.3 & 2 & 50.0 & 36 & 38.3 & \\
\hline$>75 \%$ & 10 & 43.5 & 27 & 40.3 & 1 & 25.0 & 38 & 40.4 & \\
\hline
\end{tabular}

${ }^{a} P$ value calculated using $\chi^{2}$ test comparing clinical geneticists with genetic counselors. ${ }^{b}$ Excludes three clinical geneticists and five genetic counselors who did not provide this information. 'Statistically significant $P$ value.

\section{Management strategies used and outcomes of ethical dilemmas}

Outcomes for each of the ethical dilemmas along with the three most used management strategies are presented in Table 5. It was common for respondents to have clients withdraw requests for an ethically contentious genetic test following genetic counseling. Respondents commonly consulted their peers and clinical supervisors. Respondents also used professional guidelines and the ability to refer clients to other health professionals in some instances. A range of additional management strategies were also provided to respondents within the survey, but respondents indicated use of these strategies less frequently. For example, one potential management strategy included in the survey was consultation with a clinical ethics committee, yet for 5 of the 11 ethical dilemmas, not a single respondent indicated they had used this management strategy. For the other six ethical dilemmas, the percentage of respondents who had sought advice from a clinical ethics committee ranged from $2.6 \%$ (in relation to the dilemma of misattributed paternity) to $14.3 \%$ (in relation to the dilemma of selecting for a disability).

\section{Inadvertent provision of tests deemed unethical}

Some respondents had inadvertently provided genetic tests they deemed to be unethical as a consequence of client deception or withholding of information. In these instances, respondents only became aware of their clients' true motivation for testing after the test had been provided. Three respondents reported clients requesting prenatal chromosome testing to exclude a major genetic abnormality, only to find that upon provision of results, the clients' true motivation for testing was to determine the fetal gender for the purpose of sex selection. Another respondent reported providing testing to a couple who both had achondroplasia, an autosomal dominant condition. It is common practice to provide prenatal testing in this circumstance because homozygosity for the FGFR3 mutation that underlies this condition is incompatible with life, and therefore many couples choose to terminate a pregnancy when this is found. However, the test can 
Table 3 Number of genetic health professionals who had encountered each ethical dilemma

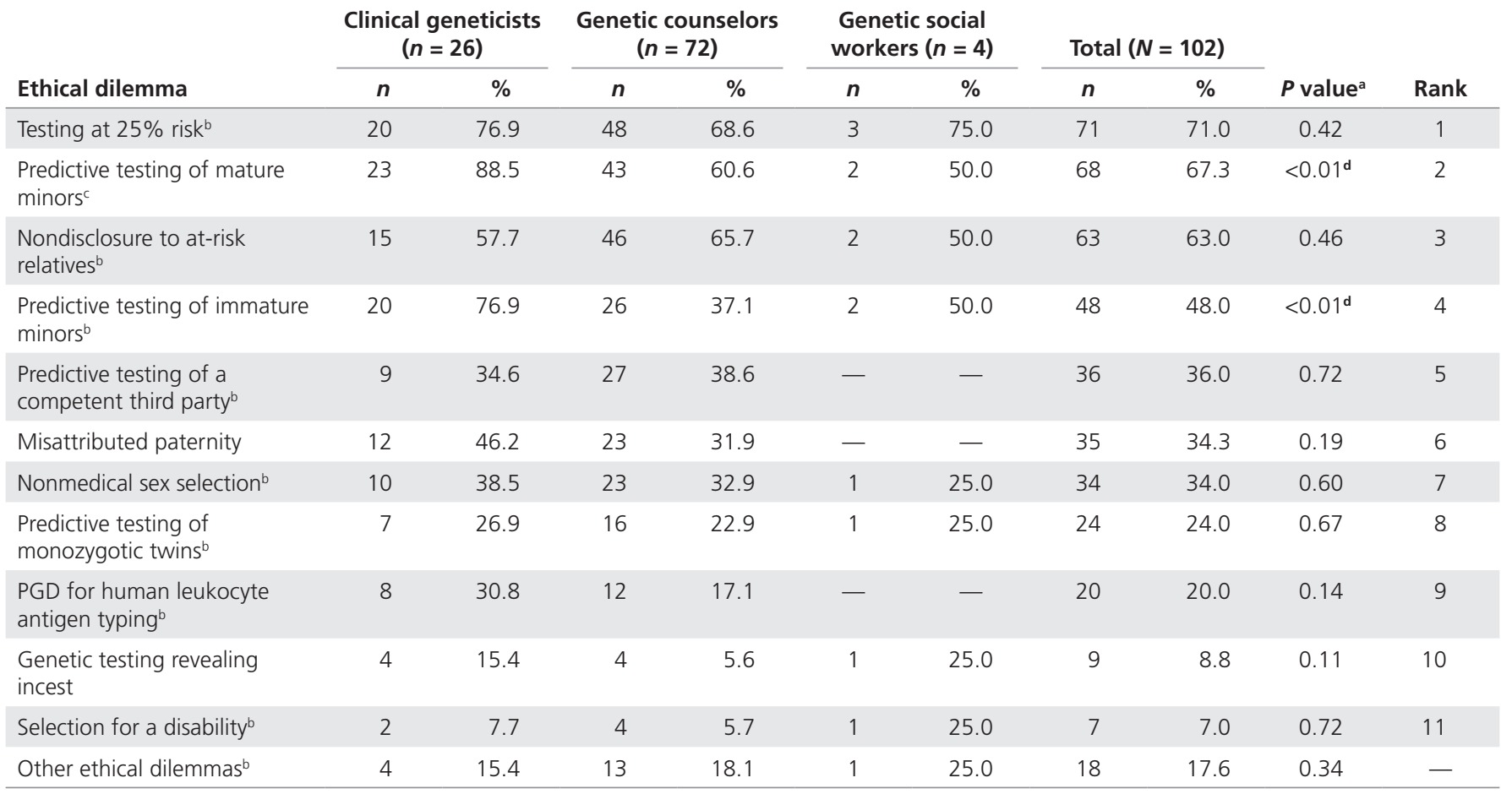

${ }^{a} P$ value was calculated with $\chi^{2}$ test comparing clinical geneticists with genetic counselors. ${ }^{b}$ Excludes two genetic counselors who did not answer this question. ${ }^{c}$ Excludes one genetic counselor who did not answer this question. dStatistically significant $P$ value.

also reveal a heterozygous fetus with achondroplasia. When testing identified a child with no FGFR3 mutation and therefore of average stature, the couple revealed their true intent, which was to terminate the pregnancy. However, in this case, after counseling, the couple elected to continue the pregnancy.

\section{DISCUSSION}

This study documented the range and frequency of ethical dilemmas regarding genetic testing encountered by Australasian genetic health professionals. The study also gathered information about the management strategies used in response to these dilemmas. The study offers an important empirical contribution to the largely theoretical discussions that currently exist regarding ethical dilemmas in clinical genetics practice. The major findings of this study were as follows: (i) a significant range of ethical dilemmas are occurring regularly in clinical genetics practice, many of which are likely to challenge genetic health professionals; (ii) a range of management strategies are used by genetic health professionals when they encounter such ethical dilemmas, with peer and clinical supervisor consultation being most commonly used and seeking advice from a clinical ethics committee rarely used; (iii) occasionally, genetic health professionals inadvertently provide tests they deem to be unethical as a consequence of client deception or withholding of information. Given that the provision of genetic testing is rapidly expanding to other areas of medicine, it is important for health professionals to increase their awareness of the range
Table 4 Additional ethical dilemmas of genetic testing encountered by genetic health professionals

\section{Ethical dilemma}

Client declined to receive results from a predictive test

Request for genetic testing for individuals who have reduced cognitive capacity or who lack social support

Carrier testing of minors

Equity of access to funding for genetic testing

Requests for release of confidential information without knowledge/ consent

Client coercion of genetic health professional

Coercion by a third party for a client to be tested

Exclusion testing in prenatal diagnosis in which there is an adult-onset autosomal dominant condition in the family ${ }^{a}$

Requests for prenatal diagnosis for human leukocyte antigen matching

Requests for genetic test results of a deceased relative

Reproductive assistance for clinically affected individuals with uncertain ability to care for a child

Requests for prenatal diagnosis for "mild" conditions

Requests for termination of pregnancy for "mild" birth defects

Sex selection against carriers of genetic conditions

aHere the grandparent from whom the gene of interest has been inherited is ascertained via linkage analysis rather than a direct test for the genetic mutation. This allows the parents to choose to terminate a pregnancy at $50 \%$ risk without learning whether the at-risk parent has the mutation or not. 
Table 5 Strategies most frequently used to manage ethical dilemmas of genetic testing, including whether the test was provided or refused

\begin{tabular}{|c|c|c|c|c|c|c|c|}
\hline Ethical dilemma & $\begin{array}{l}\text { Provided } \\
\text { testing }^{\text {a }}\end{array}$ & $\begin{array}{l}\text { Refused } \\
\text { testing }^{\text {a }}\end{array}$ & $\begin{array}{l}\text { Client } \\
\text { withdrew } \\
\text { request } \\
\text { following } \\
\text { counseling }\end{array}$ & $\begin{array}{l}\text { Client } \\
\text { withdrew } \\
\text { request on } \\
\text { own }\end{array}$ & $\begin{array}{l}\text { Most frequently } \\
\text { used strategy }\end{array}$ & $\begin{array}{l}\text { Second most } \\
\text { frequently used } \\
\text { strategy }\end{array}$ & $\begin{array}{l}\text { Third most } \\
\text { frequently used } \\
\text { strategy }\end{array}$ \\
\hline $\begin{array}{l}\text { Misattributed paternity } \\
(n=35)\end{array}$ & N/A & N/A & N/A & $\mathrm{N} / \mathrm{A}$ & $\begin{array}{l}\text { Informed mother } \\
52.6 \%\end{array}$ & $\begin{array}{l}\text { Consulted peers } \\
44.7 \%\end{array}$ & $\begin{array}{l}\text { Consulted supervisor } \\
42.1 \%\end{array}$ \\
\hline Incest $(n=9)$ & N/A & N/A & $\mathrm{N} / \mathrm{A}$ & $\mathrm{N} / \mathrm{A}$ & $\begin{array}{l}\text { Consulted peers } \\
66.7 \%\end{array}$ & $\begin{array}{l}\text { Discussed with } \\
\text { client/family } 55.6 \%\end{array}$ & $\begin{array}{l}\text { Consulted supervisor } \\
22.2 \%\end{array}$ \\
\hline $\begin{array}{l}\text { Genetic testing of } \\
\text { mature minors }(n=68)\end{array}$ & $63.2 \%$ & $26.5 \%$ & $60.3 \%$ & $5.9 \%$ & $\begin{array}{l}\text { Consulted peers } \\
61.8 \%\end{array}$ & $\begin{array}{l}\text { Consulted supervisor } \\
57.4 \%\end{array}$ & $\begin{array}{l}\text { Consulted guidelines } \\
47.1 \%\end{array}$ \\
\hline $\begin{array}{l}\text { Genetic testing of } \\
\text { immature minors } \\
(n=48)\end{array}$ & $29.2 \%$ & $56.3 \%$ & $45.8 \%$ & $4.2 \%$ & $\begin{array}{l}\text { Consulted peers } \\
58.3 \%\end{array}$ & $\begin{array}{l}\text { Consulted guidelines } \\
50.0 \%\end{array}$ & $\begin{array}{l}\text { Consulted supervisor } \\
45.8 \%\end{array}$ \\
\hline $\begin{array}{l}\text { Genetic testing of a } \\
\text { competent third party } \\
(n=36)\end{array}$ & - & $72.2 \%$ & $36.1 \%$ & $5.6 \%$ & $\begin{array}{l}\text { Consulted supervisor } \\
47.2 \%\end{array}$ & $\begin{array}{l}\text { Consulted peers } \\
30.6 \%\end{array}$ & $\begin{array}{l}\text { Informed person } \\
\text { being tested and } \\
\text { provided test } 27.8 \%\end{array}$ \\
\hline $\begin{array}{l}\text { Testing at } 25 \% \text { risk } \\
(n=71)\end{array}$ & $84.5 \%$ & $1.4 \%$ & $25.4 \%$ & $8.5 \%$ & $\begin{array}{l}\text { Asked client to } \\
\text { contact third party } \\
71.8 \%\end{array}$ & $\begin{array}{l}\text { Consulted supervisor } \\
49.3 \%\end{array}$ & $\begin{array}{l}\text { Consulted peers } \\
45.8 \%\end{array}$ \\
\hline $\begin{array}{l}\text { Nonmedical sex } \\
\text { selection }(n=34)\end{array}$ & $14.7 \%$ & $52.9 \%$ & $38.2 \%$ & $11.8 \%$ & $\begin{array}{l}\text { Consulted supervisor } \\
35.3 \%\end{array}$ & $\begin{array}{l}\text { Referred to another } \\
\text { professional } 26.5 \%\end{array}$ & $\begin{array}{l}\text { Consulted guidelines } \\
14.7 \%\end{array}$ \\
\hline $\begin{array}{l}\text { Selection for a } \\
\text { disability }(n=7)\end{array}$ & $28.6 \%$ & $57.1 \%$ & $42.9 \%$ & $14.3 \%$ & $\begin{array}{l}\text { Consulted supervisor } \\
28.8 \%\end{array}$ & $\begin{array}{l}\text { Consulted guidelines } \\
14.3 \%\end{array}$ & $\begin{array}{l}\text { Referred to ethics } \\
\text { committee } 14.3 \%\end{array}$ \\
\hline $\begin{array}{l}\text { PGD for human } \\
\text { leukocyte antigen } \\
\text { typing }(n=20)\end{array}$ & $65.0 \%$ & $10.0 \%$ & - & - & $\begin{array}{l}\text { Consulted peers } \\
45.0 \%\end{array}$ & $\begin{array}{l}\text { Consulted supervisor } \\
40.0 \%\end{array}$ & $\begin{array}{l}\text { Referred to another } \\
\text { professional } 40.0 \%\end{array}$ \\
\hline
\end{tabular}

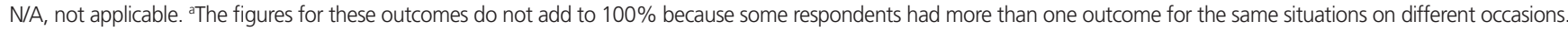

of ethical dilemmas currently occurring in relation to genetic tests and also to increase their working knowledge of potential strategies for managing these when they arise.

Each of the 11 ethical dilemmas included in the survey were encountered by at least a portion of respondents, and 14 additional ethical dilemmas were also documented. On average, genetic health professionals encountered 2.2 ethical dilemmas per year of professional practice. This indicates that genetic health professionals are encountering ethical dilemmas on a regular basis. The finding that each of the 11 ethical dilemmas included in the survey had been encountered by health professionals also indicates that existing literature concerning ethical dilemmas of clinical genetics has identified many ethical dilemmas that are relevant to current practice. The finding of 14 additional ethical dilemmas that were not included in the survey highlights that the 11 ethical dilemmas included in the survey do not constitute an exhaustive list of ethical dilemmas encountered by genetic health professionals. The variety of ethical dilemmas being encountered in current practice highlights the challenges associated with the provision of genetic tests and also the difficulties in preempting all dilemmas prospectively.
Although there were significant demographic differences between clinical geneticists and genetic counselors, significant differences were not found between these groups with regard to the number of ethical dilemmas encountered (with the exception of genetic testing of immature and mature minors).

Respondents reported that they used a range of strategies to manage the ethical dilemmas they encountered in relation to genetic testing. Two key strategies were used across the majority of ethical dilemmas. These were consulting peers (including other genetic health professionals and/or professionals from other fields, e.g., medical ethicists) and consulting clinical supervisors. Our results suggest that genetic health professionals value and rely on the experience and expertise of others when managing ethical dilemmas associated with genetic testing.

Access to clinical supervision in Australasia has become an integral aspect of practice, which is reflected in the Australasian Society of Genetic Counsellors Code of Ethics. ${ }^{36}$ Similarly, in the United Kingdom, supervision is highly recommended for genetic health professionals. ${ }^{37}$ By contrast, in the United States, clinical supervision is largely seen as a means of training genetic 
counselors rather than being used once working in this profession. ${ }^{38}$ Supervision is important for genetic health professionals in allowing space and time to think about psychosocial aspects of cases, for sharing perspectives, and exploring new ideas with a trusted supervisor or group of colleagues. ${ }^{38}$ As genetic testing moves from the genetic health profession to other areas of medicine more broadly, it may be important to consider the role of clinical supervision also, particularly in specialties in which this is not a traditional or common aspect of clinical practice.

Respondents rarely referred clients to another professional, whether it was a colleague in the genetic health profession or a colleague in a different health profession. However, the exception was the request for preimplantation genetic diagnosis to immunologically match a sibling to a sick child. Here, genetic health professionals are unable to provide the test themselves and so tend to refer to another professional who is able to do so. The lack of referral to other professionals, combined with the high rate of consultation with peers and/or a supervisor, could suggest that genetic health professionals believe they are well equipped with the necessary skills to manage these ethical dilemmas, but wish to seek reassurance and advice from other health professionals. Another possible explanation for not referring clients to other professionals is that genetic health professionals believe that doing so would disrupt the clinical and therapeutic relationship, and thus cause greater distress for the client.

Referring cases to a clinical ethics committee for review and discussion was seldom used as a management strategy by respondents. For many of the ethical dilemmas included in the survey, this strategy was not used by any respondent. Clinical ethics committees are a developing part of the Australian health system, offering timely and focused advice to clinicians facing ethical issues that arise in medicine. ${ }^{8}$ However, genetic health professionals may not be aware that this resource is available to them or may not feel that these committees have more expertise than their peers or supervisors who may be ethicists themselves or have training in ethics in cases related to genetic testing. A similar lack of referral to clinical ethics committees has been reported to occur in the United Kingdom. ${ }^{39}$

Few respondents, except in cases in which genetic testing of minors was the ethical dilemma, indicated they had consulted professional guidelines. This may be due to genetic health professionals relying on their personal moral beliefs or relying on professional codes of ethics more broadly. It might also be the case that genetic health professionals' working knowledge of existing guidelines is strong enough to eliminate the need to refer to them again. It should also be noted that guidelines do not exist for all of the ethical dilemmas included in the survey, although they do exist for some specific ethical issues, including sex selection for nonmedical reasons. More general codes of ethics have also been developed by professional genetics associations and disease-specific associations, for example, the International Huntington Association. Very little research related to the use of these guidelines by genetic health professionals has been undertaken to date.
Although genetic health professionals often refuse testing when controversial ethical dilemmas arise, in some cases, genetic health professionals reported that they had inadvertently provided genetic tests they deemed to be unethical as a consequence of client deception or withholding of information. For example, in three cases, respondents reported that clients had requested prenatal testing to exclude genetic abnormalities, only to find that the true motivation of the clients for testing had been to determine the gender for sex selection. This is an unavoidable consequence of genetic technology, yet one that is likely to leave genetic health professionals feeling uncomfortable. In these circumstances, it is important that health professionals are able to access formal de-briefing and support.

In some cases, genetic health professionals also provided tests that are viewed as highly controversial in current literature. One respondent received two requests to perform a genetic test to select a child with a $B R C A$ mutation, and the respondent reported providing the test in both cases. Mutations in $B R C A 1$ and BRCA 2 convey an increased but not absolute risk of developing cancer. Unlike the situation with conditions such as achondroplasia or deafness, for which a child without the mutation may have difficulty fitting into the specific community of affected individuals, ${ }^{22}$ there is no equivalent community for $B R C A 1 / 2$ mutation carriers. In addition, unlike the mutations associated with deafness, BRCA mutations can be life threatening. There is currently no literature concerning selection for $B R C A$ mutations, and the respondent who encountered this dilemma provided no additional information to clarify the reasons for these requests.

\section{Comparisons with other studies}

This is the first study to quantitatively document the frequency of ethical dilemmas related to genetic testing in a comprehensive way. Studies of United States, Australian, and Spainish genetic counselors have gathered information about the frequency of a variety of ethical dilemmas in clinical genetics practice, but these studies used a dichotomous variable- "frequent" or "not frequent" - which means that precise documentation of the frequencies was not possible. Also, no definition of these terms was given to respondents in these studies, and therefore respondents' interpretation of the terms "frequent" and "not frequent" might have varied. ${ }^{26-28}$ Clarke and colleagues ${ }^{14}$ used a prospective study design to document 65 instances of nondisclosure of genetic status to at-risk relatives over a 12-month period in the United Kingdom and in two Australian centers. However, nondisclosure was the only ethical dilemma related to genetic testing that was included in that study.

The series of surveys of genetic counselors from the United States, Australia, and Spain also asked respondents for strategies they would advise colleagues to use in relation to the professional and ethical issues the survey covered. ${ }^{26-28}$ The original survey revealed a variety of strategies for managing ethical concerns, including: referring to another professional, referring to professional guidelines, disregarding personal beliefs 
or biases, and determining boundaries within the family. ${ }^{28}$ Australian genetic counselors were found to use 8 of the 11 strategies referred to, ${ }^{27}$ and Spanish genetic counselors were found to use 10 of the strategies and one additional strategy-"study of the family group."26 The finding of this study, that genetic health professionals commonly seek advice from their peers, contrasts with the survey of genetic counselors in Australia, which found that only a small proportion of genetic counselors (15.4\%) would recommend discussion with other health professionals. ${ }^{27}$ Although these previous surveys have provided some information about strategies for managing ethical dilemmas, they posed only hypothetical questions, asking respondents what they would advise a colleague to do when encountering an ethical dilemma but not what they do, or have done, in their own practice. This is a key difference between our study and these past studies.

Two additional studies have examined the management strategies used by geneticists in relation to nondisclosure of genetic status to at-risk family members specifically. ${ }^{14,18}$ These found that clinical geneticists used a range of management strategies in encouraging the disclosure of genetic risk information, including: consulting colleagues, case conferences, ethics committees, published guidelines, and family letters.

\section{Study limitations and future research}

The results from this study provide validation for the extensive body of literature concerning ethical dilemmas associated with genetic testing, yet they are limited to the experiences of genetic health professionals working only in Australasia. The response rate for the survey $(31.3 \%)$ means there may be other dilemmas and management strategies that were not identified in this study and the results cannot be generalized to all genetic health professionals. The survey instrument was not validated and given that the study was retrospective, it is likely that respondent recall of the ethical dilemmas, including the frequency and the management strategies used, was not precise. It is also possible that because the lines between ethical, professional, practical, and moral dilemmas are often blurred, respondents might have omitted to report some past cases as a consequence of not perceiving them to be ethical in nature. Complementing this study with further research using a qualitative approach would be valuable in providing a better perspective regarding these biases. A prospective study would be valuable in providing accurate data on the ethical dilemmas as they occur, their frequency, and the range of management strategies used over a set period of time.

\section{Conclusion}

Demand for genetic testing is increasing, and the provision of these tests no longer falls solely to genetic health professionals, but to a range of health professionals more broadly. It is therefore important to increase awareness among the medical community about the ethical dilemmas that regularly occur in relation to genetic testing, and the ways in which these can be managed. Findings from our study indicate that health professionals who regularly provide genetic tests are likely to encounter a range of ethical dilemmas. The study also highlights the often challenging nature of such dilemmas and that, occasionally, the provision of tests deemed to be unethical is unavoidable. Health professionals providing genetic tests will require knowledge about these common ethical aspects of practice and they might also require ongoing training, support, and assistance to help navigate such dilemmas competently. Findings from this study provide an important step toward ensuring that guidance, training, education, and support are evidence based and align with current clinical practice.

\section{SUPPLEMENTARY MATERIAL}

Supplementary material is linked to the online version of the paper at http://www.nature.com/gim

\section{ACKNOWLEDGMENTS}

M.B.D. is supported by a Practitioner Fellowship from the National Health and Medical Research Council. R.E.D. is partly funded through the Invergowrie Foundation. This study was supported by the Operational Infrastructure Support Program of the Victorian government. This study was completed in partial fulfilment of the requirements for the Master of Genetic Counselling, University of Melbourne, Victoria, Australia.

\section{DISCLOSURE}

The authors declare no conflict of interest.

\section{REFERENCES}

1. Pearl PL, Pettiford JM, Combs SE, et al. Assessment of genetics knowledge and skills in medical students: insight for a clinical neurogenetics curriculum. Biochem Mol Biol Educ 2011;39:191-195.

2. Baldwin T. Understanding the opposition. Prenat Diagn 2006;26:637-645.

3. Cooley D. Deaf by design: a business argument against engineering disabled offspring. J Bus Ethics 2007;71:209-227.

4. Devolder K. Preimplantation HLA typing: having children to save our loved ones. J Med Ethics 2005;31:582-586.

5. Knoppers BM, Bordet S, Isasi RM. Preimplantation genetic diagnosis: an overview of socio-ethical and legal considerations. Annu Rev Genomics Hum Genet 2006;7:201-221.

6. Lucast EK. Informed consent and the misattributed paternity problem in genetic counseling. Bioethics 2007;21:41-50.

7. Parker M. Genetic testing in children and young people. Fam Cancer 2010;9:15-18.

8. Parker M, Lucassen A. Working towards ethical management of genetic testing Lancet 2002;360:1685-1688.

9. Savulescu J. Sex selection: the case for. Med J Aust 1999;171:373-375.

10. Savulescu J. Deaf lesbians, "designer disability" and the future of medicine. Br. Med J 2002;325:771-773

11. Wolf SM, Kahn JP, Wagner JE. Using preimplantation genetic diagnosis to create a stem cell donor: issues, guidelines \& limits. J Law Med Ethics 2003;31:327-339.

12. Arribas-Ayllon M, Sarangi S, Clarke A. Professional ambivalence: accounts of ethical practice in childhood genetic testing. J Genet Couns 2009;18:173184.

13. Asscher $E$, Koops BJ. The right not to know and preimplantation genetic diagnosis for Huntington's disease. J Med Ethics 2010;36:30-33.

14. Clarke A, Richards M, Kerzin-Storrar L, et al. Genetic professionals' reports of nondisclosure of genetic risk information within families. Eur J Hum Genet 2005; 13:556-562.

15. Dahl E, Beutel M, Brosig B, et al. Social sex selection and the balance of the sexes: empirical evidence from Germany, the UK, and the US. J Assist Reprod Genet 2006;23:311-318. 
16. Dugan RB, Wiesner $G L$, Juengst $E T$, $\mathrm{O}^{\prime}$ Riordan $\mathrm{M}$, Matthews $\mathrm{AL}$, Robin $\mathrm{NH}$ Duty to warn at-risk relatives for genetic disease: genetic counselors' clinical experience. Am J Med Genet C Semin Med Genet 2003;119C:27-34.

17. Duncan RE, Savulescu J, Gillam L, Williamson R, Delatycki MB. An international survey of predictive genetic testing in children for adult onset conditions. Genet Med 2005;7:390-396

18. Falk MJ, Dugan RB, O'Riordan MA, Matthews AL, Robin NH. Medical Geneticists' duty to warn at-risk relatives for genetic disease. Am J Med Genet A 2003:120A:374-380

19. Heimler A, Zanko A. Huntington disease: a case study describing the complexities and nuances of predictive testing of monozygotic twins. J Genet Couns 1995;4:125-137.

20. Puri S, Nachtigall RD. The ethics of sex selection: a comparison of the attitudes and experiences of primary care physicians and physician providers of clinical sex selection services. Fertil Steril 2010;93:2107-2114.

21. Schaaf CP, Scott DA, Wiszniewska J, Beaudet AL. Identification of incestuous parental relationships by SNP-based DNA microarrays. Lancet 2011;377:555556.

22. Spriggs M. Lesbian couple create a child who is deaf like them. J Med Ethics 2002;28:283.

23. Richards F, Taylor S. Social work and genetic testing: ethical issues encountered in predictive testing for Huntington's disease. Australian Social Work 1997:50:61-67.

24. Hines KA, Veach PM, LeRoy BS. Genetic counselors' perceived responsibilities regarding reproductive issues for patients at risk for Huntington disease. $J$ Genet Couns 2010;19:131-147.

25. Huggins $M$, Bloch $M$, Kanani S, et al. Ethical and legal dilemmas arising during predictive testing for adult-onset disease: the experience of Huntington disease. Am J Hum Genet 1990:47:4-12.

26. Abad-Perotín R, Asúnsolo-Del Barco Á, Silva-Mato A. A survey of ethical and professional challenges experienced by Spanish health-care professionals that provide genetic counseling services. J Genet Couns 2012;21:85-100.

27. Alliman S, Veach PM, Bartels DM, Lian F, James C, LeRoy BS. A comparative analysis of ethical and professional challenges experienced by Australian and U.S. genetic counselors. J Genet Couns 2009;18:379-394.
28. Bower MA, Veach PM, Bartels DM, LeRoy BS. A survey of genetic counselors' strategies for addressing ethical and professional challenges in practice. J Genet Couns 2002;11:163-186.

29. Lisker R, Carnevale A. Changing opinions of Mexican geneticists on ethical issues. Arch Med Res 2006:37:794-803.

30. Mariño TC, Armiñán RR, Cedeño HJ, et al. Ethical dilemmas in genetic testing: examples from the Cuban program for predictive diagnosis of hereditary ataxias. J Genet Couns 2011;20:241-248.

31. Pencarinha D, Bell N, Edwards J, Best R. A study of the attitudes and reasoning of MS genetic counselors regarding ethical issues in medical genetics. Am J Hum Genet 1991;49:326-326.

32. Veach PM, Bartels DM, LeRoy BS. Ethical and professional challenges posed by patients with genetic concerns: a report of focus group discussions with genetic counselors, physicians, and nurses. J Genet Couns 2001;10:97-119.

33. Wertz DC, Fletcher JC, eds. Ethics and Human Genetics: A Cross-Cultural Perspective. Springer-Verlag: Berlin, Germany, 1989

34. Parker M. Ethical Problems and Genetics Practice. Cambridge University Press: Cambridge, UK, 2012

35. Hansen EC. Successful Qualitative Health Research. Allen \& Unwin: NSW Australia, 2007:147

36. Australasian Society of Genetic Counsellors (ASGC). Code of Ethics. Version 1; ed 2008. https://www.hgsa.org.au/website/wp-content/ uploads/2011/03/2008GL02-ASGC-Code-of-ethics2.pdf. Accessed July 2012

37. Association of Genetic Nurses and Counsellors Supervision Working Group. Report from the UK and Eire Association of Genetic Nurses and Counsellors (AGNC) Working Group on Genetic Counselling Supervision. J Genet Couns 2007;16:127-142.

38. Kennedy AL. Supervision for practicing genetic counselors: an overview of models. J Genet Couns 2000;9:379-390.

39. Sokol DK. The unpalatable truth about ethics committees. BM 2009;339:b4179.

40. Maat-Kievit A, Vegter-Van Der Vlis M, Zoeteweij M, Losekoot M, van Haeringen A, Roos RA. Predictive testing of 25 percent individuals for Huntington disease (1987-1997). Am J Med Genet 1999;88:662-668. 